\title{
Combining magnetic resonance spectroscopy and molecular genomics offers better accuracy in brain tumor typing and prediction of survival than either methodology alone
}

\author{
LOUKAS ASTRAKAS ${ }^{1,2}$, KONSTANTINOS D. BLEKAS ${ }^{3}$, CATERINA CONSTANTINOU ${ }^{1,4}$, \\ OVIDIU C. ANDRONESI ${ }^{1,6}$, MICHAEL N. MINDRINOS ${ }^{5}$, ARISTIDIS C. LIKAS ${ }^{3}$, \\ LAURENCE G. RAHME ${ }^{4}$, PETER M. BLACK ${ }^{7}$, KAREN J. MARCUS $^{8}$ and A. ARIA TZIKA ${ }^{1,6}$
}

\begin{abstract}
${ }^{1}$ NMR Surgical Laboratory, Department of Surgery, Massachusetts General Hospital and Shriners Burn Institute, Harvard Medical School, Boston, MA 02114, USA; Departments of ${ }^{2}$ Medical Physics; ${ }^{3}$ Computer Science, University of Ioannina, Ioannina 45110, Greece; ${ }^{4}$ Molecular Surgery Laboratory, Department of Surgery, Massachusetts General Hospital and Shriners Burn Institute, Harvard Medical School, Boston, MA 02114; ${ }^{5}$ Department of Biochemistry, Stanford University School of Medicine, Stanford, CA 94305; ${ }^{6}$ Athinoula A. Martinos Center of Biomedical Imaging, Department of Radiology, Massachusetts General Hospital, Boston, MA 02114; ${ }^{7}$ Department of Neurosurgery Brigham and Women's Hospital, Harvard Medical School, Boston, MA 02115; ${ }^{8}$ Department of Radiation Oncology,

Children's Hospital, Harvard Medical School, Boston, MA 02115, USA
\end{abstract}

Received June 4, 2010; Accepted October 4, 2010

DOI: $10.3892 /$ ijo. 2011.928

\begin{abstract}
Recent advents in magnetic resonance spectroscopy (MRS) techniques permit subsequent microarray analysis over the entire human transcriptome in the same tissue biopsies. However, extracting information from such immense quantities of data is limited by difficulties in recognizing and evaluating the relevant patterns of apparent gene expression in the context of the existing knowledge of phenotypes by histopathology. Using a quantitative approach derived from a knowledge base of pathology findings, we present a novel methodology used to process genome-wide transcription and MRS data. This methodology was tested to examine metabolite and genomewide profiles in MRS and RNA in 55 biopsies from human subjects with brain tumors with $\sim 100 \%$ certainty. With the guidance of histopathology and clinical outcome, 15 genes with the assistance of 15 MRS metabolites were able to be distinguished by tumor categories and the prediction of survival was better than when either method was used alone.
\end{abstract}

Correspondence to: Dr A. Aria Tzika, NMR Surgical Laboratory, Dept. of Surgery, Massachusetts General Hospital and Harvard Medical School, 51 Blossom Street, Boston, MA 02114, USA

E-mail: atzika@hms.harvard.edu

Dr Karen Marcus, Division Radiation Oncology, Children's Hospital, Brigham and Women's Hospital, Dana Farber Cancer Institute, Harvard Medical School, 300 Longwood Avenue, Boston, MA 02115, USA

E-mail:kmarcus@1roc.harvard.edu

Key words: brain/central nervous system cancers, tumor biomarkers, ex vivo high-resolution magic angle spinning magnetic resonance spectroscopy, support vector machines, genomics
This new method, combining MRS, genomics, statistics and biological content, improves the typing and understanding of the complexity of human brain tumors, and assists in the search for novel tumor biomarkers. It is an important step for novel drug development, it generates testable hypotheses regarding neoplasia and promises to guide human brain tumor therapy provided improved in vivo methods for monitoring response to therapy are developed.

\section{Introduction}

According to the Central Brain Tumor Registry of the USA (www.cbtrus.org), the worldwide incidence rate of primary malignant brain and central nervous system (CNS) tumors, age-adjusted using the world standard population, is 3.7 per 100,000 person-years in males and 2.6 per 100,000 personyears in females. The incidence rates are higher in more developed countries (males, 5.8 per 100,000 person-years; females, 4.1 per 100,000 person-years) than in less developed countries (males, 3.0 per 100,000 person-years; females, 2.1 per 100,000 person-years).

Management of brain tumors in patients would benefit from improved characterization, diagnosis and prognostic biomarkers. The diagnostic utility of biomarkers for tissue typing lies in their biological relevance. Highly informative biomarker profiles are difficult to establish, due to current technical limitations and the small sample sizes of tissue biopsies, which pose challenges for producing accurate magnetic resonance spectroscopy (MRS) and transcriptome data. Further development and application of microscale MRS and genomics can overcome these limitations and identify new biomarkers to accurately type cancers. This report focuses on applying these technologies to brain tumors, the leading cause for high mortality in older adults $(1,2)$. 
Our hypothesis is that current tissue characterization is enhanced by developing and applying a classification strategy analysis algorithm that produces unique tumor fingerprints by combining biomarker profiles from ex vivo MRS and wholegenome expression profiling performed on microscale pediatric brain tumor biopsies. Brain-tumor specific biomarkers can be identified using high-resolution ex vivo MRS at high magnetic field strengths and a combination of microarray, bioinformatics, and computational analyses. In the near future, combining clinical MRI, MRS and MR imaging of gene expression in vivo should produce superior images to enhance the specificity of cancer diagnosis in clinical medicine. Knowledge acquired from these studies can also be used to type inoperable cancers. This hypothesis builds upon prior reports (3-16). Prior data have provided the following information and advances: a) measurements using one-dimensional (1D) ex vivo HighResolution Magic Angle Spinning (HRMAS) proton $\left({ }^{1} \mathrm{H}\right) \mathrm{MRS}$ at $9.4 \mathrm{~T}$ correlated directly with the neuropathology of intact brain tumor biopsies. The intracellular metabolite phosphocholine (PCho), a constituent of the choline (Cho) peak, was associated with cellularity and proliferative activity (17); b) MRS-detectable lipid changes were implicated in brain tumor apoptosis and necrosis (17); c) in vivo MRS spectra correlated with ex vivo MRS measurements (17); d) Gene expression analyses of embryonal CNS tumors distinguished between tumor types that could not be clearly distinguished by histopathology $(18,19)$; e) HRMAS ${ }^{1} \mathrm{H}$ MRS and genomic analyses of microscale tissue biopsies ( 2 $\mathrm{mg}$ ) yielded quality data, enabling MRS-derived metabolites and gene expression differences to be related and cross validated (15); f) an optimized adiabatic solid-state NMR method, Total ThroughBond Spectroscopy (TOBSY), maximized the advantages of HRMAS applied to intact biopsies when compared to more conventional liquid-state NMR approaches $(20,21)$; g) a structured network knowledge-based approach was demonstrated to be capable of analyzing genome-wide transcriptional responses in the context of known functional interrelationships among proteins, small molecules, and phenotypes (13); and h) the design and initial testing of our classification algorithms was successful (22).

While considerable work has been done on the classification of cancers based on genomic data (23-33), and some work has been done using MRS data (22,34-42), these two datasets have yet to be integrated along with other clinical features. We hope to improve cancer diagnosis accuracy immediately following biopsy collection by uncovering and exploiting complementary information in the MRS and genomic data. We undertook this challenge by employing machine-learning methods that combine the data generated from MRS and genomics. Our rationale for using methods that emerged under the machine-learning framework, such as the support vector machines (SVM), is that these methods have already been employed successfully for cancer classification for more than ten years $(25,32,43-45)$ and have replaced other traditional methods such as linear discriminant analysis, logistic regression, density-based methods (Parzen window, Naïve Bayes), neural networks with PCA pre-processing, and decision trees (32). As a result of its wide acceptance as a state-of-the-art method for gene-based diagnosis, the SVM constitutes an important module of modern software tools for gene expression analysis
(46). On the other hand, statistical methods are limited mostly to the task of ranking individual genes with respect to their ability to act as individual markers, thus they can be useful in the feature selection task. Also, the SVM approach has been proposed for classification of heterogeneous data sources using a weighted combination of multiple similarity measures (kernels), (one kernel for each data source). This methodology has already been successfully applied in several medical diagnosis tasks $(47,48)$ and is a promising technique for combining data from multiple sources. In our line of research, the data sources to be combined are genomics, MRS, and clinical data. Here, we report that a new classification system using the sensor fusion approach, which combines genomics, MRS, statistics and biological content, improves the typing and understanding of the complexity of human brain tumors, as well as the search for novel tumor biomarkers, an important step for novel drug development. It also generates testable hypotheses regarding neoplasia and promises to guide human brain tumor therapy provided that improved in vivo methods for monitoring response to therapy are developed.

\section{Materials and methods}

Experimental design. We carried out experiments on a dataset of 55 gene expression profiles derived from normal (9 cases) and tumor (46 cases) classes. The tumor class samples belonged to three categories: high grade $(\mathrm{H})$ [20 cases, 12 glioblastoma multiforme (GBM); 8 anaplastic astrocytoma (AA)], low grade (L) (17 cases, 7 meningioma; 7 schwanoma; 7 pylocytic astrocytoma) and metastasized (M) (11 cases, 5 adenocarcinoma; 3 breast cancer metastasis; 3 other metastasis). Subjects ranged in age from 17 to 54 years.

HRMAS ${ }^{1} H$ MRS using adiabatic TOBSY. We used a previously designed 2D ex vivo HRMAS ${ }^{1} \mathrm{H}$ MRS procedure for brain tumors, based on novel concepts rooted in solid-state NMR spectroscopy (49). All HRMAS ${ }^{1} \mathrm{H}$ MRS using TOBSY experiments were performed on a Bruker BioSpin Avance NMR spectrometer $(600.13 \mathrm{MHz})$ using a 4-mm triple resonance $\left({ }^{1} \mathrm{H},{ }^{13} \mathrm{C},{ }^{2} \mathrm{H}\right)$ HRMAS probe (Bruker). Specimens were pre-weighed and transferred to a $\mathrm{ZrO}_{2}$ rotor tube $(4 \mathrm{~mm}$ diameter, $50 \mu \mathrm{l}$ ), containing an external standard [trimethylsilyl propionic-2,2,3,3-d4 acid (TSP), $\left.\mathrm{M}_{\mathrm{w}}=172, \mathrm{~d}=0.00 \mathrm{ppm}\right]$ that functioned as a reference both for resonance chemical shift and quantification. The HRMAS ${ }^{1} \mathrm{H}$ MRS was performed at $-8^{\circ} \mathrm{C}$ with $3 \mathrm{kHz}$ MAS speed to minimize tissue degradation. Typical acquisition parameters were, $2 \mathrm{k}$ points direct dimension (13 ppm spectral width), 200 points indirect dimension (7.5 ppm spectral width), 8 scans with 2 dummy scans, $1 \mathrm{sec}$ water pre-saturation, $2 \mathrm{sec}$ total repetition time, $45 \mathrm{msec}$ mixing time and total acquisition time $45 \mathrm{~min}$.

Analysis of 2D TOBSY MR spectra. The spectra of intact specimens were analyzed using the XWINNMR 3.5 software package (Bruker Biospin Corp, Billerica, MA). Before Fourier transformation and phasing, the $2 \mathrm{D}$ free induction decays were subjected to QSINE=3 window apodization. Baseline correction was then performed using a low order spline function. After Lorentzian and/or Gaussian fitting, the area under the curves or the volumes of the 15 most intense spectra resonances were 
calculated. Relative quantification using the TSP standard was performed as described below. These resonances were identified and assigned to the corresponding metabolites.

Quantification of brain metabolites from the 2D TOBSY MR spectra. To quantify the brain metabolites, we used the ratio of the cross peak volumes of the metabolites $[\mathrm{CPV}(\mathrm{M})]$ to the TSP diagonal peak volume [DPV(TSP)]. This ratio was further divided by the biopsy weight (w) to yield the normalized metabolite intensity, $\mathrm{I}_{\mathrm{c}}=1 / \mathrm{w} \times \mathrm{CPV}(\mathrm{M}) / \mathrm{DPV}(\mathrm{TSP})$.

Microscale transcriptome analyses to determine the gene expression profiles of the tumor biopsy samples after HRMAS ${ }^{1} H M R S$. We performed microscale genome array studies with the commercially available Affymetrix U133Plus ${ }^{\circledR}$ array (Santa Clara, CA).

Platform choice. The Affymetrix GeneChip ${ }^{\circledR}$ DNA microarray platform has several significant advantages over competing technologies, including coverage of the entire human genome, access to probe sequences, probe redundancy (11 sequences per gene) to optimize fidelity of the signal-tonoise ratio, ready commercial availability, standardization of hybridization, washing, staining and scanning processes, quality control built into the manufacturing processes, available technical support, and a relatively low cost per investigated gene.

RNA purification. Total experimental RNA were isolated from the biopsy samples used for $H R M A S{ }^{1} H M R S$. Total control RNA was isolated from normal tissue removed along with the tumor biopsies, or from age-matched patients undergoing epilepsy surgery. RNA was isolated using the modified protocol of the RNeasy purification kit (Qiagen) that our Stanford colleagues have optimized. Briefly, during tissue homogenation and deproteination, $1 \mathrm{mg}$ of tRNA and $10 \mathrm{mg}$ linear polyacrylamide are added as carriers. This greatly improves RNA yields to $500 \mathrm{ng}$ of total RNA per mg of tissue, an amount $\times 20$ greater than that required for our optimized RNA labeling procedure. RNA purity was assessed from the OD 260/280 ratio, with only samples having ratios $>1.9$ retained for further use. In addition, RNA integrity was assessed by the Agilent 2100 Bioanalyzer, where good quality samples exhibit a relatively flat and low baseline in the capillary electrophoresis elution and have $18 \mathrm{~S}$ and $28 \mathrm{~S}$ peaks between 1:1 to 1:2, as scored by the Bioanalyzer software.

$R N A$ labeling. We used the Ribo-SPIA protocol (www.nugeninc.com) for mRNA labeling and amplification. Ribo-SPIA is superior to all other labeling methods, when the amount of RNA is $<1 \mathrm{mg}$. An overview of the Ribo-SPIA amplification process was described previously by Tzika et al, (15). We used 20 ng total RNA for first strand cDNA synthesis, and the entire procedure for amplification, fragmentation and labeling was performed in one day.

Data analysis of gene expression. The expression profiles of tumor biopsies analyzed and compared to those of control tissue. Specifically, the raw Affymetrix CEL files were normalized and analyzed to obtain expression values using both dChip (http://biosun1.harvard.edu/complab/dchip/) and GC-RMA $(50,51)$. Both sets of obtained expression values analyzed (as described below) and the results from the two methods were compared. We used significant analysis of

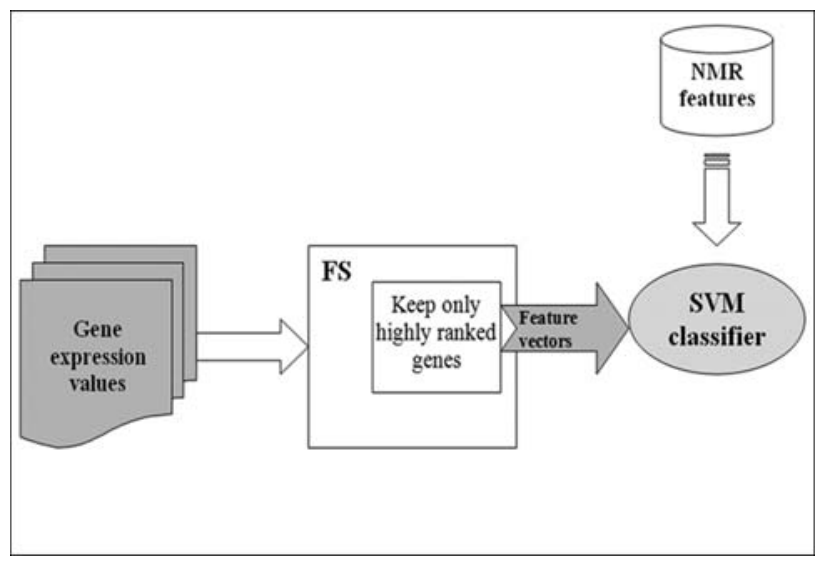

Figure 1. Classification system architecture.

microarrays (SAMs) (http://www-stat.stanford.edu/ tibs/SAM/) to obtain a list of differentially expressed genes with a false discovery rate (q-value) $<0.05$ and to properly take into account the substantial multiple comparison problem $(52,53)$. BRBArray Tools (http://linus.nci.nih.gov/BRB-ArrayTools.html) were used to classify tumor types based on expression patterns, using several major built-in methods including SVM and Bayesian classifier. BRB-Array software was used to divide samples into training and test datasets and to perform gene selection and model building in each cross-validation run of the training dataset. This cross-validation ensured an unbiased final predication accuracy for the test dataset. The top genes selected by the classifiers were clustered and visualized in dChip. The enriched Gene Ontology and pathway groups in these top genes were identified by dChip and Ingenuity Pathway Analysis software and correlated with pathways implicated in CNS tumorigenesis. Analysis results were produced in both tabular and graphical formats.

Classification strategy. The architecture of our classification system is shown in Fig. 1. We first fine-tuned the feature selection process by which the high dimensionality of the SMAs output was reduced by selecting only the most relevant genes for the classification task. Then, a classifier was constructed to these reduced feature vectors in order to optimally partition the space according to class. We chose to use the SVM classifier (54). Finally, the constructed reduced feature space from the gene expression values was combined with the NMR features in order to examine their impact on the classifier.

Feature selection $(F S)$. Feature selection methods typically rank genes according to their differential expressions among phenotypes and pick the top-ranked genes. There are two general schemes for feature selection, filters and wrappers $(50,55)$. We used the minimum redundancy - maximum relevance (MRMR) method (51), because it is a powerful framework for selecting features that capture class characteristics in a broad spectrum by reducing mutual redundancy within the feature set. Thus, it offers greater robustness and generalization properties to the reducing feature space of samples, which can significantly improve classification accuracy. 


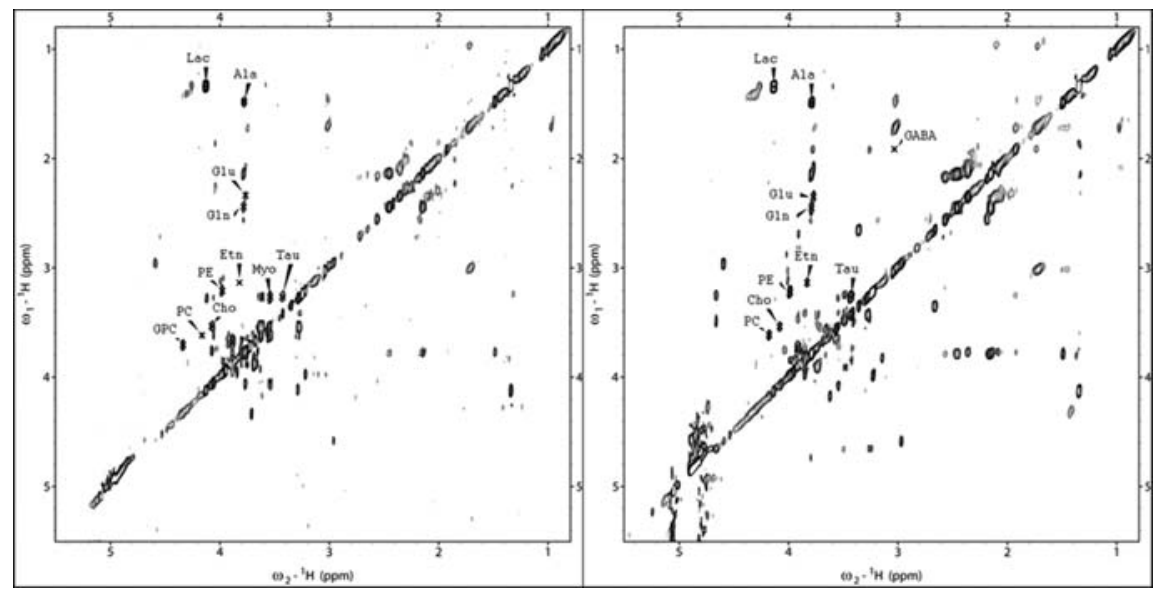

Figure 2. Typical TOtal Through-Bond SpectroscopY (TOBSY) using ex vivo HRMAS MRS on anaplastic astrocytoma (left) and meningioma (right) biopsies. HRMAS ${ }^{~} \mathrm{H}$ MR spectra using TOBSY, with $45 \mathrm{msec}$ mixing time, $3 \mathrm{kHz}$ MAS speed, and $-8^{\circ} \mathrm{C}$ at $600 \mathrm{MHz}$. (Ala, alanine; Cho, choline; GABA, $\gamma$-aminobutyric acid; Gln, glutamine; Glu, glutamate; GPC, glycerophosphocholine; Lip, lipids; Myo, myoinositol; PC, phosphocholine; PE, phosphoethanolamine; PUFA, polyunsaturated fatty acids; Tau, taurine). Note that Cho, PC, GPC, PE, Etn, are clearly separable here due to the use of the 2D TOBSY method. Also note that the anaplastic astrocytoma (high-grade) exhibits different MR spetrum as compared to meningioma (low-grade).

SVM classifier. SVM (54) is a very powerful classification method that draws hyperplanes in the feature vector space by maximizing the margin between data samples of different classes. SVM is built upon the use of kernels to construct nonlinear decision boundaries. Here, we used linear kernels and the LIBSVM environment for multi-class SVMs (52). It should be noted that during all experiments with SVM, we adopted the standard leave-one-out training/testing scheme. That is, one element of the data was used as a training set, and the left-out element was used for testing the predictive performance of the resulting classifier. The SVM soft-margin constant $C$ was set to 10 , chosen based on the results of a few runs on one training set. The results indicated that the value of this parameter was not crucial for our experimental dataset.

Statistical analysis. Multiple stepwise logistic regression analysis was done to evaluate whether genomic and/or HRMAS MRS data can predict clinical outcome. Maximum likelihood estimation of the logistic model provided coefficients, SEs, adjusted odds ratios, $95 \%$ confidence intervals, the likelihood ratio $\chi^{2}$ test for parameters as well as sensitivity, specificity and accuracy of the prediction of the clinical outcome. Statistical analysis was conducted with the SPSS software package (version 16.0, SPSS Inc., Chicago, IL), and two-tailed Pvalues of $<0.05$ were considered statistically significant.

\section{Results}

The impact of each the following 16 NMR features on the classifier were examined, alanine (Ala), aspartate (Asp), choline (Cho), ethanolamine (Etn), $\gamma$-aminobutyric acid (GABA), glutamine (Gnl), glutamate (Glu), glycerophosphocholine (GPC), lactate (Lac), lipids (Lip), myoinositol (Myo), $\mathrm{N}$-acetyl aspartate (NAA), phosphocholine (PC), phospho-ethanolamine (PE), polyunsaturated fatty acids (PUFA) and taurine (Tau). Typical 2D TOBSY MR spectra are shown in Fig. 2.

A classification strategy analysis algorithm to identify combinatorial biomarker profiles that uniquely define tumor

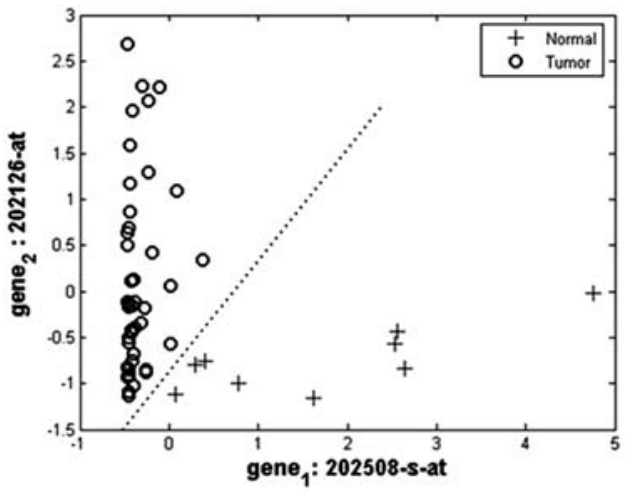

Figure 3. The rich feature space created by the two first selected genes (shown in $\mathrm{x}$ and $\mathrm{y}$ axis) that is linearly divided into normal and tumor class regions; 202126_at is PRP4-pre-mRNA processing factor 4 (gene symbol, PRPF4B); 202508_s_at is synaptosomal associated protein, $25 \mathrm{kDa}$ (gene symbol SNAP25). Further details on the biological function(s) of these genes and correlation with diseases are included in Table I.

types. Two classification problems were studied: i) distinguishing between normal and tumor classes. All 46 samples of the three tumor categories belonged to the same parent-class, tumor (two-class problem); ii) studying the different tumor categories ( $\mathrm{H}, \mathrm{L}$ and $\mathrm{M}$ ) and subtypes i.e., GBM, AA, meningioma, etc. Experiments were designed for the 55-9=46 samples in an attempt to distinguish among the different types of tumors (multiple-class problem). In the twoclass problem, the performance of the SVM classifier using gene values was perfect. In particular, we obtained 100\% accuracy using only the first two features (genes 202126-at and 202508-s-at) that were selected by the MRMR feature selection method. As shown in Fig. 3, their discriminative ability was highy significant as they established a feature space, which could be easily divided into normal and tumor sub-regions. The ability of two other genes to discriminate between tumor (either high grade or low grade) and metastasis is summarized in Fig. 4. Gene 1552797_s_at is relevant to a 


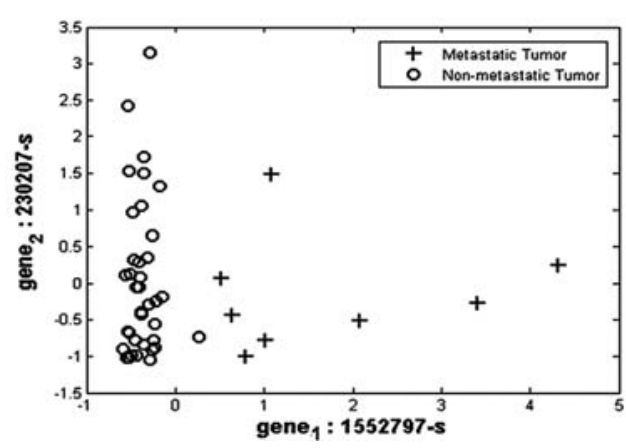

Figure 4. The rich feature space created by the two genes shown in the $\mathrm{x}$ and y axis with discriminatory ability between tumor and metastasis; 230207_s_at is dedicator to cytokinesis 5 proteing (gene symbol, DOCK5); 1552797_s_at is prominin 2 (gene symbol, PROM2). Further details on these genes biological function(s) and correlation with diseases are included in Table I.

stem cell marker for malignant brain tumors, cd133 (53); iii) tumor typing and subtype classification. As expected, this classification scheme was more difficult. The classifier had near excellent behavior using the first 9-25 features selected by the MRMR method (Table I). Using the first 15 genes, the classifier reached $100 \%$ best accuracy. Specifically, after adding gene 209771_x_at to the feature vectors, the classification performance was $80.4 \%$; adding gene 229851 s_at increased the performance to $91.3 \%$; adding gene 225491_at increased it to $95.6 \%$; adding genes 211991_s_at, 1552797_s_at, 224209_s_at, 206349_at, 204131_s_at and 241938_at increased it to $97.8 \%$. Finally, the addition of gene 204501_at increased the classification performance to $100 \%$ for anaplastic astrocytoma and meningioma. We also tested the impact of combining selected NMR features (isolated or combined) with gene values. Using all 15 NMR features and selected genes (obtained from the MRMR genes selection method) increased the classification performance from $95.6 \%$ to $97.8 \%$ for the high grade typing (11 genes and 15 NMR features), from $95.6 \%$ to $100 \%$ for schwannoma subtyping (1 gene 209169_at and 15 NMR features) and from $95.6 \%$ to $97.8 \%$ for metastasis subtyping (12 genes and 15 NMR features).

Studies demonstrating the potential of HRMAS combined with gene expression profiles offer better accuracy than each methodology alone in predicting survival. We performed multiple stepwise logistic regression analysis to evaluate how gene expression values, HRMAS MRS data, and their combination predict survival. We chose the 15 best genes according to their MRMR algorithm rank (Table II) and 15 metabolite values (Ala, Asp, Cho, Etn, GABA, Gln, Glu, GPC, Lac, Lip, Myo, NAA, PC, PE, PUFA, Tau), (see above) corresponding to 49 available binary clinical outcomes (33 survived vs. 16 deceased). Our preliminary results have proven that the combination of genomic and HRMAS MRS data improves the ability to predict clinical outcome. More specifically, gene data alone achieved high sensitivity, predicting 15 out of 16 deceased cases (sensitivity 94\%), high specificity, predicting 32 out of 33 cases (specificity 97\%), and high accuracy (96\%). HRMAS MRS data had inferior sensitivity $(11 / 16,69 \%)$, specificity $(28 / 32,85 \%)$, and accuracy (80\%). Combining genomics and HRMAS MRS data logistic regression achieved a perfect classification (100\% for all indices) of survived and diseased cases. Although we believe that these promising results are affected by sample size, they clearly demonstrate that the combination of gene expression and MRS data predict a clinically meaningful parameter, such as survival, better than either technique alone.

\section{Discussion}

Our objective in this study was to use a novel approach that combines biomarkers detected with magnetic resonance spectroscopy (MRS) and molecular genomics to improve the characterization and prognostication of biospecimens in molecular medicine. We aimed to develop a useful clinical tool that uses tissue fingerprinting to aid clinicians not only in making diagnostic and treatment course decisions, but also in understanding the biology of brain malignancy subtypes in humans, an important step for novel drug development. The method is based on the development of a classification strategy analysis algorithm that combines biomarker profiles generated using high-resolution ex vivo MRS and wholegenome expression analyses of microscale brain tumor samples as well as features from the clinical patient database (i.e., survival). We optimized and applied ex vivo HRMAS ${ }^{1} \mathrm{H}$ MRS and transcriptome profiling to intact tumor biopsies that are $<2 \mathrm{mg}$. We then combined these data sets to develop a classification strategy analysis algorithm to produce tissue fingerprints that accurately type these biopsies and demonstrated the potential of HRMAS and its combination with gene expression profiles to offer better accuracy than each methodology alone in predicting survival.

Herein, we demonstrated for the first time that a combined approach of using metabolite and gene expression profiles allows for more accurate discernment of tumor categories and better prediction of patient survival than either method alone. Previous data have shown that metabolites derived from brain proton MRS predict clinically meaningful parameters such as treatment response and survival of children with CNS tumors $(10,56,57)$. Gene expression has been reported to predict outcome and survival with greater accuracy than histology $(18,19)$. Prior studies have demonstrated that ex vivo MRS can be used to classify brain tumors with high sensitivity, specificity, and accuracy using only 16 metabolites, which is the highest number of metabolites detected with in vivo $2 \mathrm{D}$ approaches (22). Importantly, the agreement between ex vivo and in vivo MRS data suggests that in vivo $2 \mathrm{D}$ MRS provides a means of typing inoperable tumors in the absence of biopsies or gene expression data. It was thus important to train our algorithm (which can handle missing data) with multiple kinds of information, including both MRS and gene expression data, to increase its discriminatory capability that will also allow its application in vivo and specifically in cases of inoperable tumors. Although the ability to produce tissue MRS data noninvasively using $2 \mathrm{D}$ in vivo $\mathrm{MRS}$ would provide a considerable advantage, it is beyond the scope of the current investigation. In vivo MRS is clinically feasible and we have used it previously to investigate whether ex vivo and in vivo MRS data agree (17). We found that such agreement exists and thus obviates the use of in vivo MRS to guide ex vivo biopsy collection for 


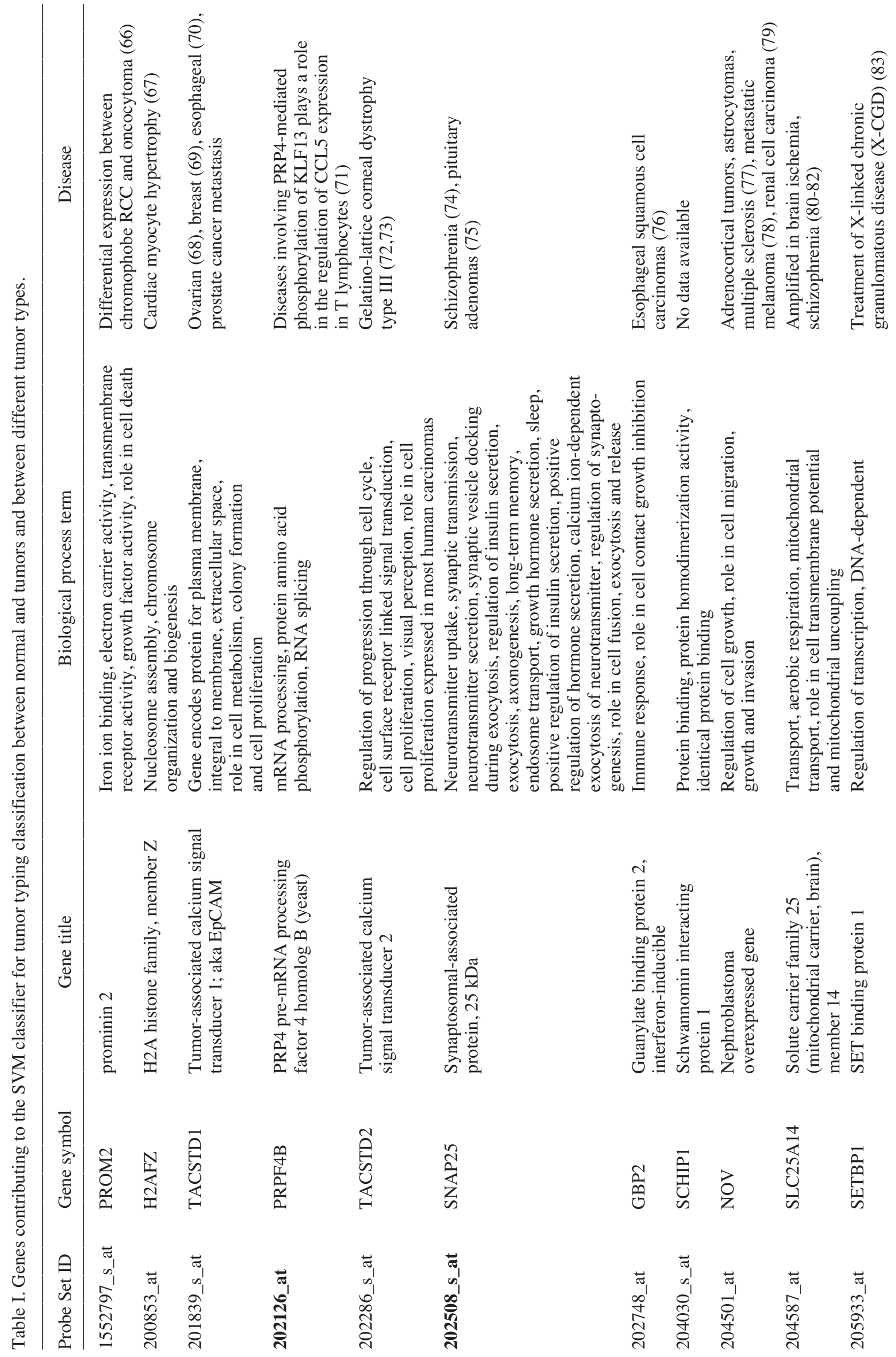




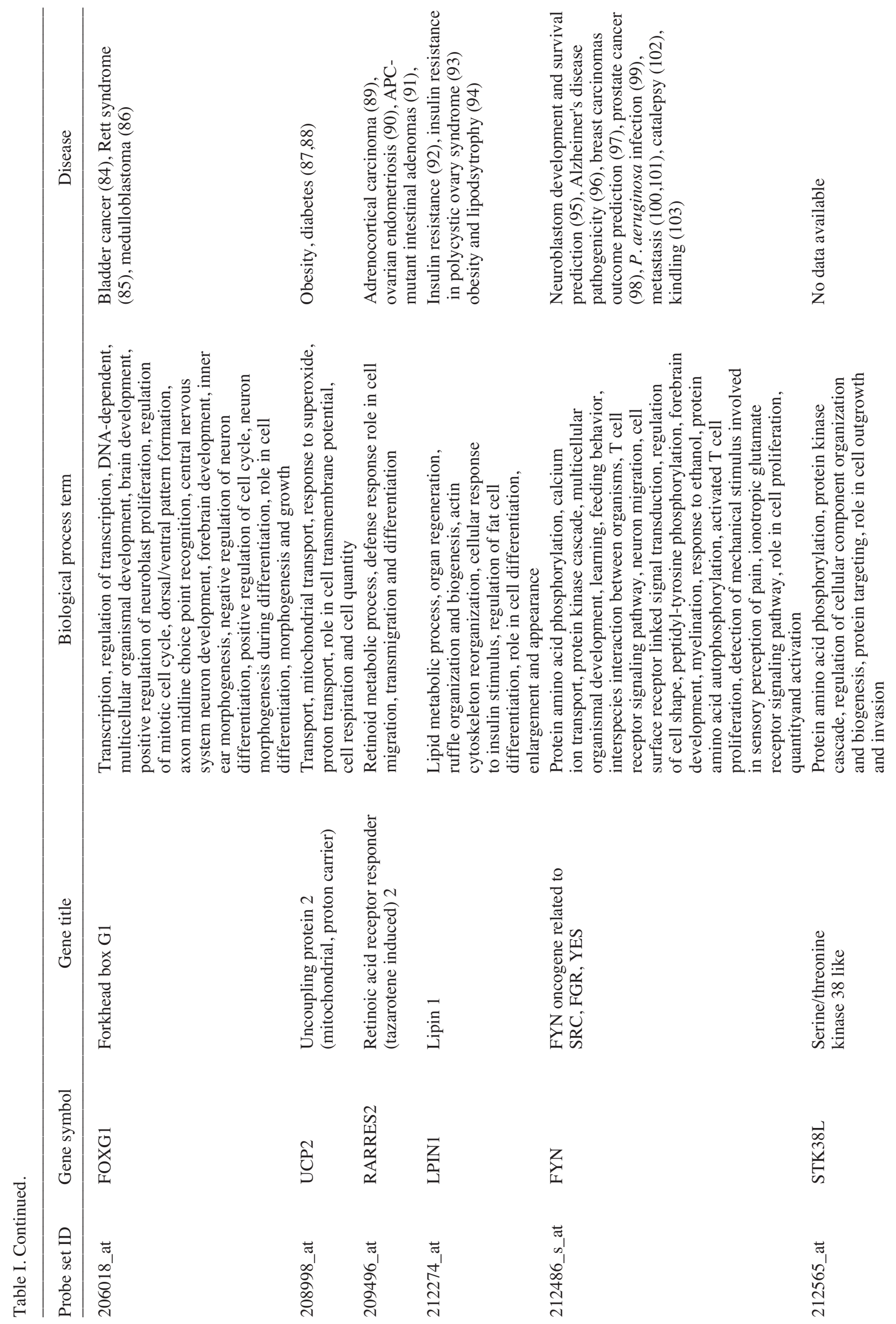




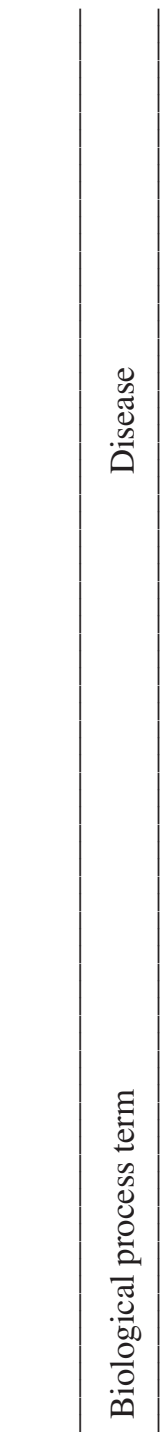

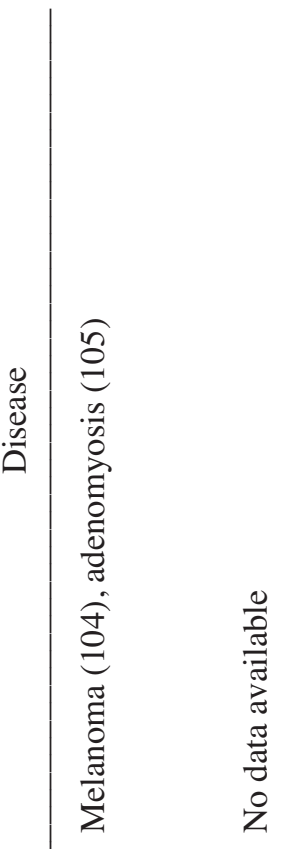

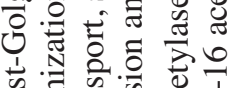

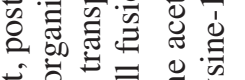

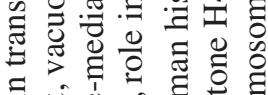

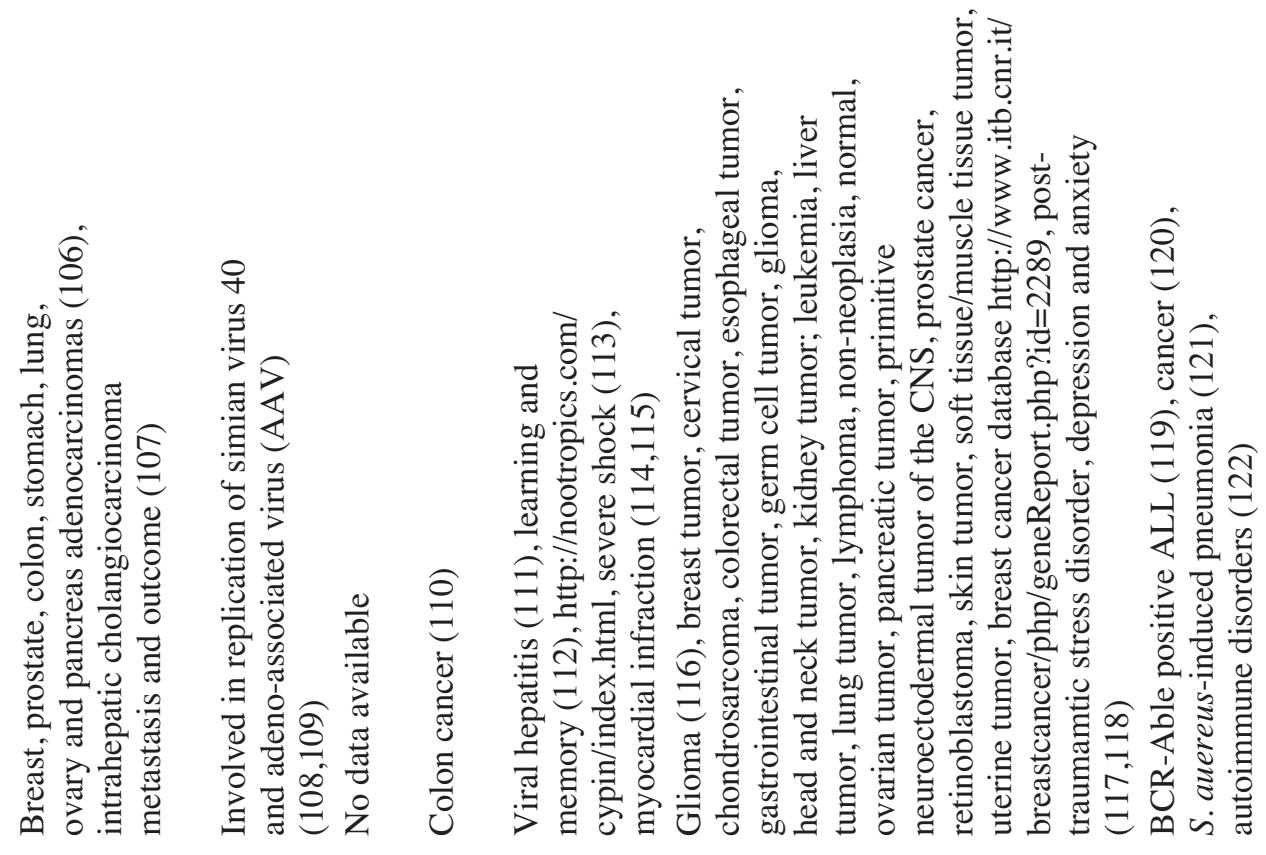

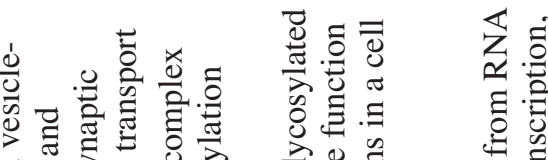

कू

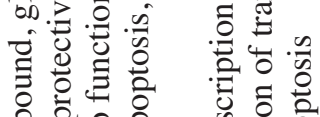

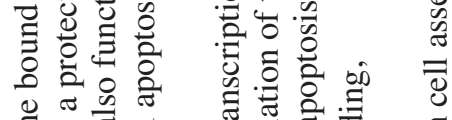

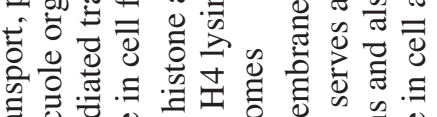

可

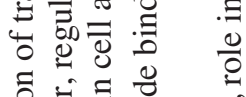
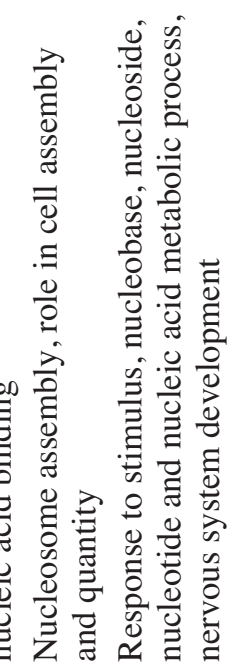

0
0
0
00
0
0
$=0$
0
.$\Xi$
0
0
0
00
0
0
0
0
0
0
0
0

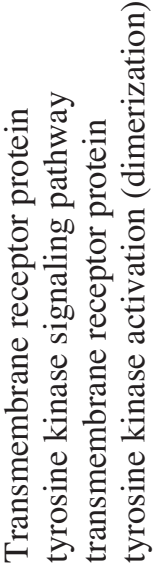

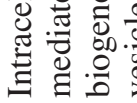

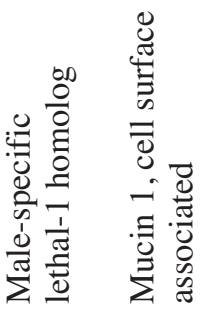
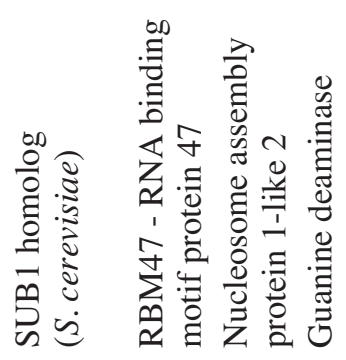

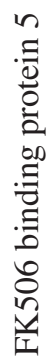
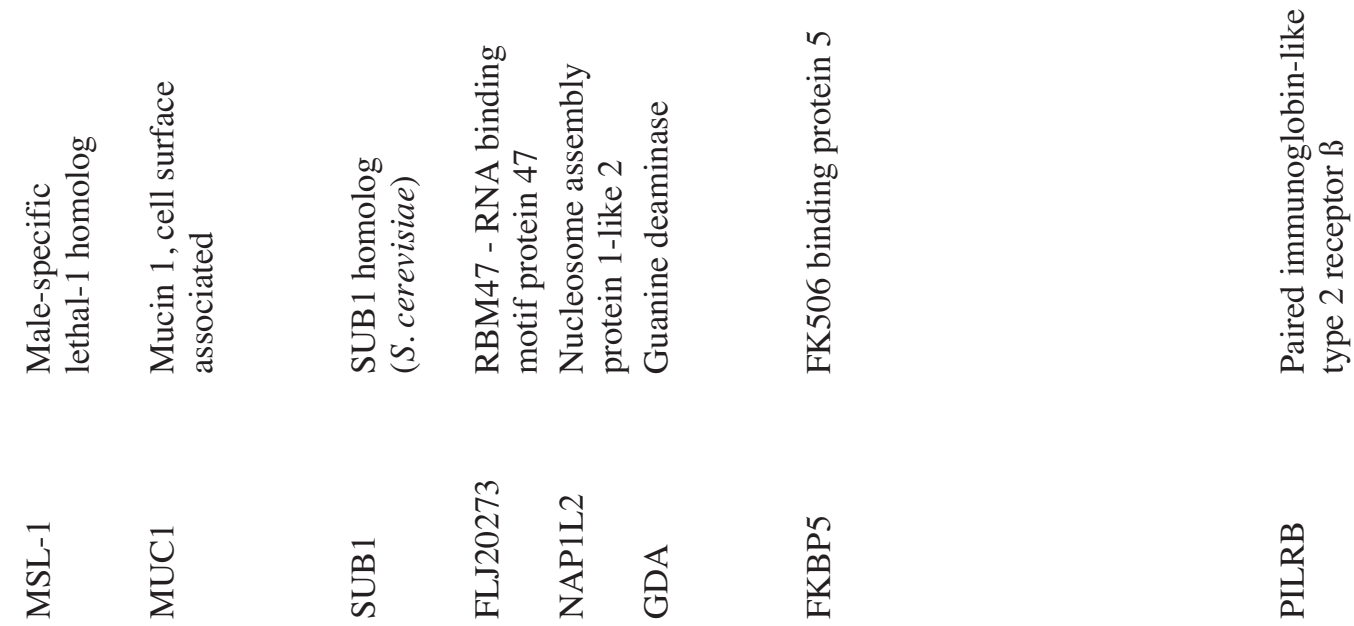

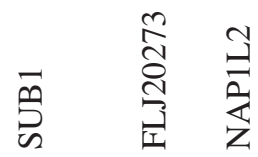

$\stackrel{n}{\frac{0}{2}}$

咅

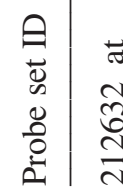

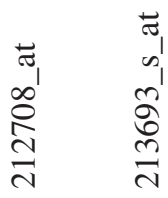

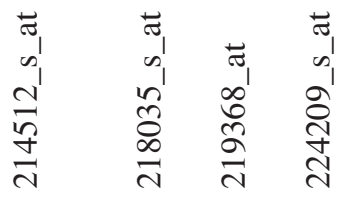

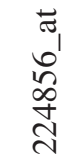

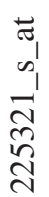




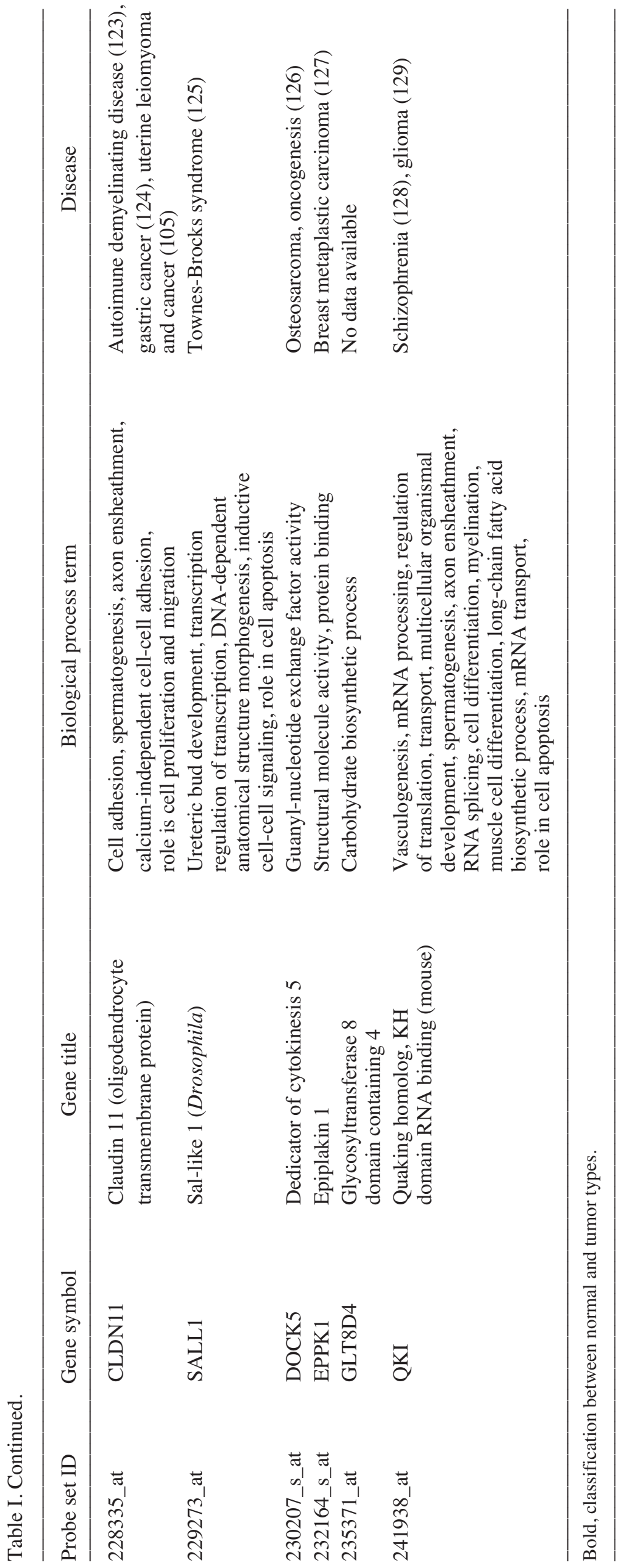




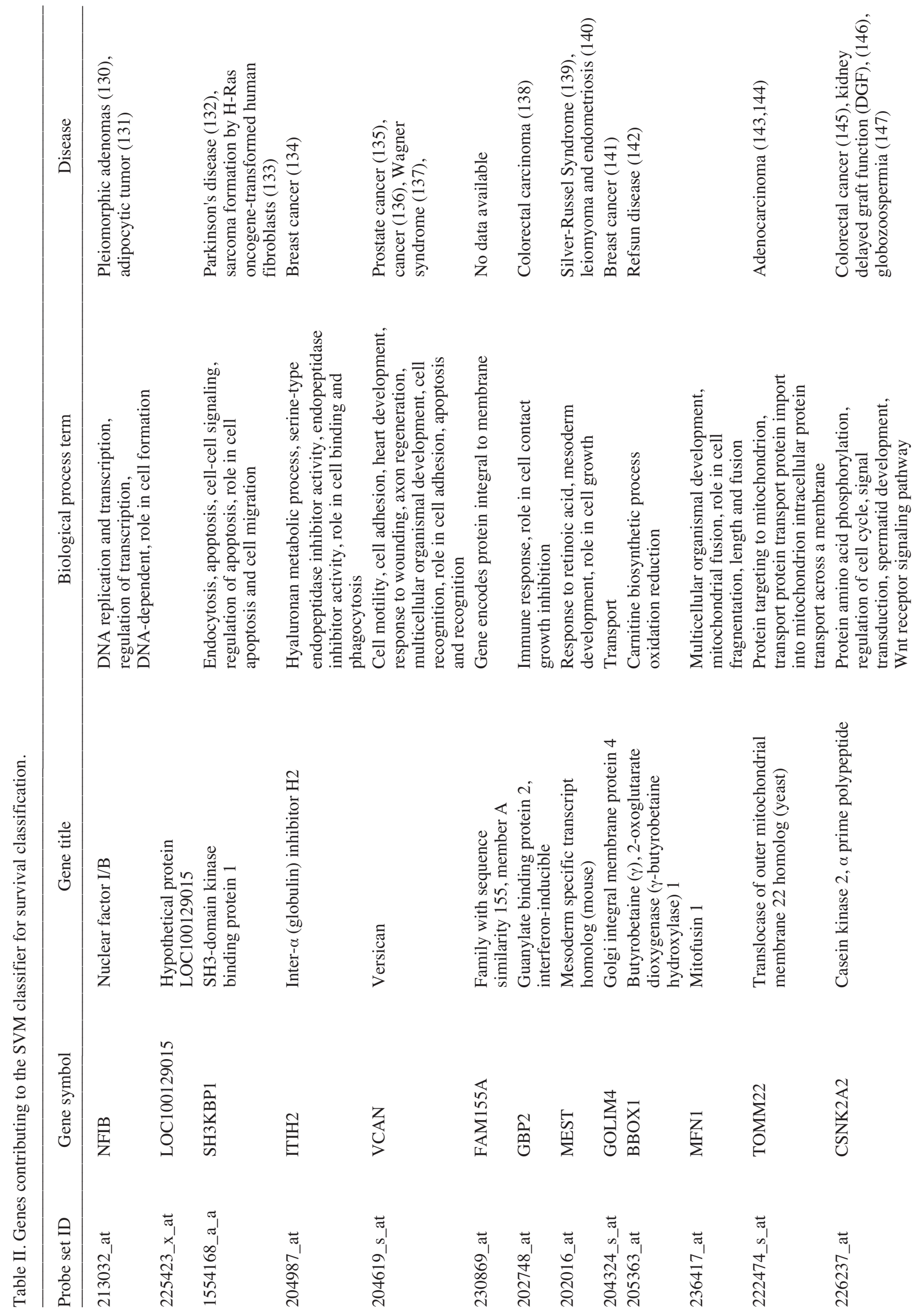


achieving the goals of this study. In the current study, all biopsies were collected from patients undergoing surgery. Given that these in vivo tests are considered to be 'additional' and not 'standard' tests for patients in pain prior to their operation, it would have been ethically ill-advised to persuade parents to agree to additional tests unless such studies were medically indicated. However, if such data are available in the future, they will be provided for inclusion in our analysis, by the assisting oncologist in the clinical data collection.

We believe that in vivo 2D MRS will be useful for typing inoperable tumors in the absence of biopsies or gene expression data for two reasons. Firstly, ex vivo MRS can be used to classify brain tumors with high sensitivity, specificity, and accuracy using only 16 metabolites (22), which is the highest number of metabolites detected with in vivo $2 \mathrm{D}$ approaches. Secondly, there is agreement between the ex vivo and in vivo MRS data obtained. Accordingly, it will be critical that we train our algorithm (which is able to handle missing data) with both MRS and gene expression data as well as with other available data to increase its discriminatory capability.

We found that certain genes were useful to subtype brain tumors (Table I) and certain other genes were useful for survival classification (Table II). These genes have been reported for other cancers or diseases (see references within Tables) but are novel to brain tumors. The ability of two genes only to discriminate between two types of brain tumors (either high grade or low grade) and metastasis was excellent (Fig. 4). It is interesting that gene 1552797_s_at is relevant to a stem cell marker for malignant brain tumors, cd133 (53). This suggests that our work using adult brain tumor biopsies has demonstrated that with appropriate quality control, we are able to produce meaningful data and introduce a novel classification scheme that complements and substantiates the current hypothesis of cancer stem cells (53) as a means of determining brain tumor classification and treatment.

Furthermore, our work validates and extends previous work on classification strategy analysis algorithms for both in vivo and in vitro spectra from MRS (34-40). One of the principal difficulties in such analyses is the large number of metabolites that may contribute to the spectra, each with relative intensities that can greatly vary, even in samples of the same type (34). Nonetheless, even early studies reported that the spectra of body fluids obtained with MRS are systematically different between tumor patients and healthy individuals. In many cases, successful differentiation using both linear and nonlinear methods can be made based on single resonance peaks or ratios of resonance ranges (35). More recent work on brain tumors has shown that classification according to histological type and grade is possible using similar approaches, particularly linear discriminant analysis (LDA) after feature extraction with independent components analysis (ICA) in a Bayesian framework (41) or correlation analysis and stepwise LDA (36) or using belief networks (42) or using Support Vector Machines (SVMs) (22).

Also, our approach in fusing genomics and MRS to improve the typing and prognosis of human brain tumors agrees with the notion that fusion of different sources of information can improve system performance and facilitate detection, recognition, identification, tracking, change detection, and decision-making in defense, robotics, and 
medicine $(58,59)$. Some studies have previously described that classifiers have attempted to combine data from different sources (60-63). We believe that an efficient fusion scheme using complementary information can improve confidence.

Finally, results garnered from this study may lead to the development of new clinical tools to better assess operable cancers via tissue fingerprinting and to facilitate the distinction of tumor types that cannot be readily distinguished histopathologically (64) or with routine neuroimaging (65). This will enable neurooncologists, neuropathologists, neurosurgeons and neurologists to make informed decisions related to tumor type, grade, and treatment options. The results may also facilitate the clinical application of lower resolution in vivo MRS to inoperable cancers using metabolic biomarkers to monitor anticancer therapies, in order to improve patient survival and quality of life. More importantly, they will further elucidate the biology of brain malignancy subtypes in brain tumor patients, an important step for novel drug development. Thus, these results greatly increase the overall potential for success of future studies that combine clinical MRI, MRS and MR imaging of gene expression in vivo to produce improved combined images, which could then be used to readily discriminate between metastasis and high-grade gliomas, a distinction not made adequately at present (60).

\section{Acknowledgements}

The study was supported in part by discretional funds to A. Aria Tzika. The authors thank the Departments of Surgery and Radiology at Massachusetts General Hospital, as well as Neurosurgery and Pathology at Brigham and Women's Hospital Boston for supporting this study. We thank John Passanese, first year medical student at Harvard Medical for assistance with references cited in Tables. We also thank Drs Ann Power Smith and Kathryn Edmondson of Write Science Right for editorial assistance.

\section{References}

1. Legler JM, Ries LA, Smith MA, et al: Cancer surveillance series [corrected]: brain and other central nervous system cancers: recent trends in incidence and mortality. J Natl Cancer Inst 91: 1382-1390, 1999.

2. Segal G: Re: Brain and other central nervous system cancers: recent trends in incidence and mortality. J Natl Cancer Inst 92: $77-78,2000$

3. Tzika AA, Vajapeyam S and Barnes PD: Multivoxel proton MR spectroscopy and hemodynamic MR imaging of childhood brain tumors: preliminary observations. AJNR Am J Neuroradiol 18: 203-218, 1997.

4. Cheng L, Anthony D, Comite A, Black P, Tzika A and Gonzalez R: Quantification of microheterogeneity in glioblastoma multiforme with ex vivo high-resolution magic-angle spinning (HRMAS) proton magetic resonance spectroscopy. Neuro Oncol 2: 87-95, 2000.

5. Tzika A, Khong P, Astrakas L and Zarifi M: Functional MRI of childhood brain neoplasms. J Hong Kong College Radiol 3: S54-S59, 2000

6. Tzika A, Zurakowski D, Poussaint T, et al: Proton magnetic resonance spectroscopic imaging of the child's brain: the response of tumors to treatment. Neuroradiology 43: 169-177, 2001.

7. Tzika AA, Zarifi MK, Goumnerova L, et al: Neuroimaging in pediatric brain tumors: Gd-DTPA-enhanced, hemodynamic, and diffusion MR imaging compared with MR spectroscopic imaging. AJNR Am J Neuroradiol 23: 322-333, 2002.

8. Tzika AA, Astrakas LG, Zarifi MK, et al: Multiparametric MR assessment of pediatric brain tumors. Neuroradiology 45: 1-10, 2003
9. Astrakas LG, Zurakowski D, Tzika AA, et al: Noninvasive magnetic resonance spectroscopic imaging biomarkers to predict the clinical grade of pediatric brain tumors. Clin Cancer Res 10: 8220-8228, 2004

10. Tzika AA, Astrakas LG, Zarifi MK, et al: Spectroscopic and perfusion magnetic resonance imaging predictors of progression in pediatric brain tumors. Cancer 100: 1246-1256, 2004.

11. Astrakas LG, Goljer I, Yasuhara S, et al: Proton NMR spectroscopy shows lipids accumulate in skeletal muscle in response to burn trauma-induced apoptosis. FASEB J 19: 1431-1440, 2005.

12. Padfield KE, Astrakas LG, Zhang Q, et al: Burn injury causes mitochondrial dysfunction in skeletal muscle. Proc Natl Acad Sci USA 102: 5368-5373, 2005.

13. Calvano SE, Xiao W, Richards DR, et al: A network-based analysis of systemic inflammation in humans. Nature 437: 1032-1037, 2005.

14. Wang Y, Makedon FS, Ford JC and Pearlman J: HykGene: a hybrid approach for selecting marker genes for phenotype classification using microarray gene expression data. Bioinformatics 21: 1530-1537, 2005.

15. Tzika AA, Astrakas L, Cao HH, et al: Combination of highresolution magic angle spinning proton magnetic resonance spectroscopy and microscale genomics to type brain tumor biopsies. Int J Mol Med 20: 199-208, 2007.

16. Tzika AA: Proton magnetic resonance spectroscopic imaging as a cancer biomarker for pediatric brain tumors (Review). Int J Oncol 32: 517-526, 2008.

17. Tzika AA, Cheng LL, Goumnerova L, et al: Biochemical characterization of pediatric brain tumors by using in vivo and ex vivo magnetic resonance spectroscopy. J Neurosurg 96: 1023-1031, 2002

18. Pomeroy SL, Tamayo P, Gaasenbeek M, et al: Prediction of central nervous system embryonal tumour outcome based on gene expression. Nature 415: 436-442, 2002.

19. Nutt CL, Mani DR, Betensky RA, et al: Gene expression-based classification of malignant gliomas correlates better with survival than histological classification. Cancer Res 63: 1602-1607, 2003.

20. Andronesi OC, Mintzopoulos D, Struppe J, Black P and Tzika AA: Enhanced sensitivity for multidimensional highresolution magic-angle-spining H1-MR-spectroscopy. In: International Society for Magnetic Resonanse in Medicine, p776, 2008.

21. Andronesi OC, Mintzopoulos D, Struppe J, Black PM and Tzika AA: Solid-state NMR adiabatic TOBSY sequences provide enhanced sensitivity for multidimensional high-resolution magicangle-spinning 1H MR spectroscopy. J Magn Reson 193: 251-258, 2008.

22. Andronesi OC, Blekas KD, Mintzopoulos D, Astrakas L, Black PM and Tzika AA: Molecular classification of brain tumor biopsies using solid-state magic angle spinning proton magnetic resonance spectroscopy and robust classifiers. Int J Oncol 33: 1017-1025, 2008

23. Eisen MB, Spellman PT, Brown PO and Botstein D: Cluster analysis and display of genome-wide expression patterns. Proc Natl Acad Sci USA 95: 14863-14868, 1998.

24. Yeang C, Ramaswamy S, Tamayo P, et al: Molecular classification of multiple tumor types. Bioinformatics 17: S316-S322, 2001.

25. Ramaswamy S, Tamayo P, Rifkin R, et al: Multiclass cancer diagnosis using tumor gene expression signatures. Proc Natl Acad Sci USA 98: 15149-15154, 2001.

26. Klein U, Tu Y, Stolovitzky A, et al: Gene expression profiling of B cell chronic lymphocytic leukemia reveals a homogeneous phenotype related to memory B cells. J Exp Med 194: 1625-1638, 2001.

27. Macgregor P and Squire J: Application of microarrays to the analysis of gene expression in cancer. Clin Chem 48: 1170-1177, 2002.

28. Sherlock G: Analysis of large-scale gene expression data. Curr Opin Immunol 12: 201-205, 2000.

29. Hoffmann R, Seidl T and Dugas M: Profound effect of normalization on detection of differentially expressed genes in oligonucleotide microarray data analysis. Genome Biol 3: R33, 2002.

30. Holter N, Mitra M, Maritan A, Cieplak M, Banavar J and Federoff N: Fundamental patterns underlying gene expression profiles: simplicity from complexity. Proc Natl Acad Sci USA 97: 8409-8414, 2000

31. Raychaudhuri S, Stuart J and Altman R: Principal components analysis to summarize microarray experiments: application to sporulation time series. Pac Symp Biocomput pp455-466, 2000. 
32. Brown M, Grundy W, Lin D, et al: Knowledge-based analysis of microarray gene expression data by using support vector machines. Proc Natl Acad Sci USA 97: 262-267, 2000.

33. Mendez M, Hodar C, Vulpe C, Gonzalez M and Cambiazo V: Discriminant analysis to evaluate clustering of gene expression data. FEBS Lett 522: 24-28, 2002.

34. Lisboa P, Kirby S, Vellido A, Lee Y and El-Deredy W: Assessment of statistical and neural networks methods in NMR spectral classification and metabolite selection. NMR Biomed 11: 225-234, 1998 .

35. Hagberg G: From magnetic resonance spectroscopy to classification of tumors: A review of pattern recognition methods NMR Biomed 11: 148-156, 1998.

36. Tate AR, Majos C, Moreno A, Howe FA, Griffiths JR and Arus C: Automated classification of short echo time in in vivo $1 \mathrm{H}$ brain tumor spectra: a multicenter study. Magn Reson Med 49: 29-36, 2003.

37. Devos A, Lukas L, Suykens JA, et al: Classification of brain tumours using short echo time $1 \mathrm{H}$ MR spectra. J Magn Reson 170: 164-175, 2004

38. Lukas L, Devos A, Suykens JA, et al: Brain tumor classification based on long echo proton MRS signals. Artif Intell Med 31 : 73-89, 2004

39. Tate AR, Underwood J, Acosta DM, et al: Development of a decision support system for diagnosis and grading of brain tumours using in vivo magnetic resonance single voxel spectra. NMR Biomed 19: 411-434, 2006.

40. Opstad KS, Ladroue C, Bell BA, Griffiths JR and Howe FA: Linear discriminant analysis of brain tumour (1)H MR spectra: a comparison of classification using whole spectra versus metabolite quantification. NMR Biomed 20: 763-770, 2007.

41. Huang Y, Lisboa PJG and El-Deredy W: Tumour grading from magnetic resonance spectroscopy: A comparison of feature extraction with variable selection. Stat Med 22: 147-164, 2003.

42. Reynolds GM, Peet AC and Arvanitis TN: Generating prior probabilities for classifiers of brain tumours using belief networks. BMC Med Inform Decis Mak 7: 27, 2007.

43. Simon R: Diagnostic and prognostic prediction using gene expression profiles in high-dimensional microarray data. $\mathrm{Br}$ Cancer 89: 1599-1604, 2003

44. Ancona N, Maglietta R, Piepoli A, et al: On the statistical assessment of classifiers using DNA microarray data. BMC Bioinformatics 7: 387, 2006.

45. Statnikov A, Wang L and Aliferis CF: A comprehensive comparison of random forests and support vector machines for microarray-based cancer classification. BMC Bioinformatics 9 . 319, 2008

46. Simon R, Lam A, Li MC, Ngan M, Menenzes S and Zhao Y: Analysis of gene expression data using BRB-array tools. Cancer Inform 3: 11-17, 2007.

47. Gilchrist MA, Salter LA and Wagner A: A statistical framework for combining and interpreting proteomic datasets. Bioinformatics 20: 689-700, 2004

48. Lanckriet GR, De Bie T, Cristianini N, Jordan MI and Noble WS: A statistical framework for genomic data fusion. Bioinformatics 20: 2626-2635, 2004.

49. Andronesi OC, Mintzopoulos D, Struppe J, Black PM and Tzika AA: Solid-state NMR adiabatic TOBSY sequences provide enhanced sensitivity for multidimensional high-resolution magic-angle-spinning (1)H MR spectroscopy. J Magn Reson 193: 251-258, 2008

50. Saeys Y, Inza I and Larranaga P: A review of feature selection techniques in bioinformatics. Bioinformatics 23: 2507-2517, 2007.

51. Ding $\mathrm{C}$ and Peng $\mathrm{H}$ : Minimum redundancy feature selection from microarray gene expression data. J Bioinform Comput Biol 3: 185-205, 2005 .

52. Hsu CW and Lin CJ: A comparison of methods for multiclass support vector machines. IEEE Trans Neural Netw 13: 415-425, 2002.

53. Sakariassen PO, Immervoll $\mathrm{H}$ and Chekenya $\mathrm{M}$ : Cancer stem cells as mediators of treatment resistance in brain tumors: status and controversies. Neoplasia 9: 882-892, 2007.

54. Vapnik V: Statistical Learning Theory. Haykin S (ed). Wiley-Interscience, New York, 1998.

55. Guyon I and Elisseeff A: An introduction to variable and future selection. J Mach Learn Res 3: 1157-1182, 2003

56. Astrakas L, Zurakowski D, Marcus KJ, et al: Proton MRS biomarkers predict survival in children with CNS tumors. In: International Society for Magnetic Resonance in Medicine, Miami, p145, 2005
57. Marcus KJ, Astrakas LG, Zurakowski D, et al: Predicting survival of children with CNS tumors using proton magnetic resonance spectroscopic imaging biomarkers. Int J Oncol 30: 651-657, 2007.

58. Hall DL and Linas J: Handbook of Multisensor Data Fusion. CRC Press, 2001

59. Roemer MJ, Kacprzynski GJ and Orsagh RF: Assessment of data and knowledge fusion strategies for prognostics and health management. In: Aerospace Conference 2001 IEEE. Big Sky, MT, pp2979-2988, 2001.

60. De Edelenyi FS, Rubin C, Esteve F, et al: A new approach for analyzing proton magnetic resonance spectroscopic images of brain tumors: nosologic images. Nat Med 6: 1287-1289, 2000.

61. Simonetti AW, Melssen WJ, Szabo de Edelenyi F, van Asten JJ, Heerschap A and Buydens LM: Combination of feature-reduced MR spectroscopic and MR imaging data for improved brain tumor classification. NMR Biomed 18: 34-43, 2005.

62. Galanaud D, Nicoli F, Chinot O, et al: Noninvasive diagnostic assessment of brain tumors using combined in vivo MR imaging and spectroscopy. Magn Reson Med 55: 1236-1245, 2006.

63. Luts J, Heerschap A, Suykens JA and Van Huffel S: A combined MRI and MRSI based multiclass system for brain tumour recognition using LS-SVMs with class probabilities and feature selection. Artif Intell Med 40: 87-102, 2007

64. Lakhani SR and Ashworth A: Microarray and histopathological analysis of tumours: the future and the past? Nat Rev Cancer 1: 151-157, 2001

65. Julia-Sape M, Acosta D, Majos C, et al: Comparison between neuroimaging classifications and histopathological diagnoses using an international multicenter brain tumor magnetic resonance imaging database. J Neurosurg 105: 6-14, 2006.

66. Rohan S, Tu JJ, Kao J, et al: Gene expression profiling separates chromophobe renal cell carcinoma from oncocytoma and identifies vesicular transport and cell junction proteins as differentially expressed genes. Clin Cancer Res 12: 6937-6945, 2006.

67. Chen IY, Lypowy J, Pain J, et al: Histone H2A.z is essential for cardiac myocyte hypertrophy but opposed by silent information regulator 2alpha. J Biol Chem 281: 19369-19377, 2006.

68. Heinzelmann-Schwarz VA, Gardiner-Garden M, Henshall SM et al: Overexpression of the cell adhesion molecules DDR1, Claudin 3, and Ep-CAM in metaplastic ovarian epithelium and ovarian cancer. Clin Cancer Res 10: 4427-4436, 2004.

69. Spizzo G, Gastl G, Wolf D, et al: Correlation of COX-2 and EpCAM overexpression in human invasive breast cancer and its impact on survival. Br J Cancer 88: 574-578, 2003.

70. Kimura H, Kato H, Faried A, et al: Prognostic significance of EpCAM expression in human esophageal cancer. Int J Oncol 30: 171-179, 2007

71. Huang B, Ahn YT, McPherson L, Clayberger C and Krensky AM: Interaction of PRP4 with Kruppel-like factor 13 regulates CCL5 transcription. J Immunol 178: 7081-7087, 2007.

72. Jing Y, Liu C and Wang L: A novel TACSTD2 mutation identified in two Chinese brothers with gelatinous drop-like corneal dystrophy. Mol Vis 15: 1580-1588, 2009.

73. Alberti S, Miotti S, Stella M, et al: Biochemical characterization of Trop-2, a cell surface molecule expressed by human carcinomas: formal proof that the monoclonal antibodies T16 and MOv-16 recognize Trop-2. Hybridoma 11: 539-545, 1992.

74. Corradini I, Verderio C, Sala M, Wilson MC and Matteoli M SNAP-25 in neuropsychiatric disorders. Ann NY Acad Sci 1152: 93-99, 2009.

75. Rotondo F, Kovacs K, Scheithauer BW, et al: Immunohistochemical expression of SNAP-25 protein in adenomas of the human pituitary. Appl Immunohistochem Mol Morphol 16: 477-481, 2008

76. Guimaraes DP, Oliveira IM, de Moraes E, et al: Interferoninducible guanylate binding protein (GBP)-2: a novel p53regulated tumor marker in esophageal squamous cell carcinomas. Int J Cancer 124: 272-279, 2009.

77. Thibout H, Martinerie C, Creminon C, et al: Characterization of human NOV in biological fluids: an enzyme immunoassay for the quantification of human NOV in sera from patients with diseases of the adrenal gland and of the nervous system. J Clin Endocrinol Metab 88: 327-336, 2003.

78. Vallacchi V, Daniotti M, Ratti F, et al: CCN3/nephroblastoma overexpressed matricellular protein regulates integrin expression, adhesion, and dissemination in melanoma. Cancer Res 68: 715-723, 2008

79. Niu Z, Ito M, Awakura Y, et al: The expression of NOV and WT1 in renal cell carcinoma: a quantitative reverse transcriptasepolymerase chain reaction analysis. J Urol 174: 1460-1462, 2005. 
80.Ho PW, Chu AC, Kwok KH, Kung MH, Ramsden DB and Ho SL: Knockdown of uncoupling protein-5 in neuronal SHSY5Y cells: Effects on MPP+-induced mitochondrial membrane depolarization, ATP deficiency, and oxidative cytotoxicity. J Neurosci Res 84: 1358-1366, 2006.

81. Nakase T, Yoshida Y and Nagata K: Amplified expression of uncoupling proteins in human brain ischemic lesions. Neuropathology 27: 442-447, 2007.

82. Yasuno K, Ando S, Misumi S, et al: Synergistic association of mitochondrial uncoupling protein (UCP) genes with schizophrenia. Am J Med Genet B Neuropsychiatr Genet 144: B250-B253, 2007.

83. Ott MG, Schmidt M, Schwarzwaelder K, et al: Correction of $\mathrm{X}$-linked chronic granulomatous disease by gene therapy, augmented by insertional activation of MDS1-EVI1, PRDM16 or SETBP1. Nat Med 12: 401-409, 2006.

84. Kim TH, Jo SW, Lee YS, et al: Forkhead box O-class 1 and forkhead box G1 as prognostic markers for bladder cancer. J Korean Med Sci 24: 468-473, 2009.

85. Ariani F, Hayek G, Rondinella D, et al: FOXG1 is responsible for the congenital variant of Rett syndrome. Am J Hum Genet 83: 89-93, 2008

86. Adesina AM, Nguyen Y, Mehta V, et al: FOXG1 dysregulation is a frequent event in medulloblastoma. J Neurooncol 85: 111-122, 2007.

87. Fleury C, Neverova M, Collins S, et al: Uncoupling protein-2: a novel gene linked to obesity and hyperinsulinemia. Nat Genet 15: 269-272, 1997.

88. O'Rahilly S: Uncoupling protein 2: Adiposity angel and diabetes devil? Nat Med 7: 770-772, 2001.

89. Fernandez-Ranvier GG, Weng J, Yeh RF, et al: Identification of biomarkers of adrenocortical carcinoma using genomewide gene expression profiling. Arch Surg 143: 841-846, 2008.

90.Zafrakas M, Tarlatzis BC, Streichert T, et al: Genome-wide microarray gene expression, array-CGH analysis, and telomerase activity in advanced ovarian endometriosis: a high degree of differentiation rather than malignant potential. Int J Mol Med 21: 335-344, 2008.

91. Segditsas S, Sieber O, Deheragoda M, et al: Putative direct and indirect Wnt targets identified through consistent gene expression changes in APC-mutant intestinal adenomas from humans and mice. Hum Mol Genet 17: 3864-3875, 2008.

92. Yao-Borengasser A, Rasouli N, Varma V, et al: Lipin expression is attenuated in adipose tissue of insulin-resistant human subjects and increases with peroxisome proliferator-activated receptor gamma activation. Diabetes 55: 2811-2818, 2006.

93. Mlinar B, Pfeifer M, Vrtacnik-Bokal E, Jensterle M and Marc J: Decreased lipin 1 beta expression in visceral adipose tissue is associated with insulin resistance in polycystic ovary syndrome. Eur J Endocrinol 159: 833-839, 2008

94. Reue K: The role of lipin 1 in adipogenesis and lipid metabolism. Novartis Foundation Symposium 286: 58-203 2007.

95. Berwanger B, Hartmann O, Bergmann E, et al: Loss of a FYNregulated differentiation and growth arrest pathway in advanced stage neuroblastoma. Cancer Cell 2: 377-386, 2002.

96. Ho GJ, Hashimoto M, Adame A, et al: Altered p59Fyn kinase expression accompanies disease progression in Alzheimer's disease: implications for its functional role. Neurobiol Aging 26: 625-635, 2005.

97. Charpin C, Secq V, Giusiano S, et al: A signature predictive of disease outcome in breast carcinomas, identified by quantitative immunocytochemical assays. Int J Cancer 124: 2124-2134, 2009.

98.Posadas EM, Al-Ahmadie H, Robinson VL, et al: FYN is overexpressed in human prostate cancer. BJU Int 103: 171-177, 2009.

99.Esen M, Grassme H, Riethmuller J, Riehle A, Fassbender K and Gulbins E: Invasion of human epithelial cells by Pseudomonas aeruginosa involves src-like tyrosine kinases p60Src and p59Fyn. Infect Immun 69: 281-287, 2001

100. Takayama T, Mogi Y, Kogawa K, et al: A role for the fyn oncogene in metastasis of methylcholanthrene-induced fibrosarcoma A cells. Int J Cancer 54: 875-879, 1993.

101. Huang J, Asawa T, Takato T and Sakai R: Cooperative roles of Fyn and cortactin in cell migration of metastatic murine melanoma. J Biol Chem 278: 48367-48376, 2003.

102. Hattori K, Uchino S, Isosaka T, et al: Fyn is required for haloperidol-induced catalepsy in mice. J Biol Chem 281: 7129-7135, 2006
103. Kojima N, Ishibashi H, Obata K and Kandel ER: Higher seizure susceptibility and enhanced tyrosine phosphorylation of $\mathrm{N}$-methyl-D-aspartate receptor subunit $2 \mathrm{~B}$ in fyn transgenic mice. Learn Mem 5: 429-445, 1998.

104. Stromberg S, Agnarsdottir M, Magnusson K, et al: Selective expression of Syntaxin-7 protein in benign melanocytes and malignant melanoma. J Proteome Res 8: 1639-1646, 2009.

105. Hever A, Roth RB, Hevezi PA, et al: Molecular characterization of human adenomyosis. Mol Hum Reprod 12: 737-748, 2006.

106. Ho SB, Niehans GA, Lyftogt C, et al: Heterogeneity of mucin gene expression in normal and neoplastic tissues. Cancer Res 53: 641-651, 1993.

107. Shibahara H, Tamada S, Higashi M, et al: MUC4 is a novel prognostic factor of intrahepatic cholangiocarcinoma-mass forming type. Hepatology 39: 220-229, 2004

108. Muramatsu S, Handa A, Kajigaya S and Brown KE: Transcription-positive cofactor 4 enhances rescue of adenoassociated virus genome from an infectious clone. J Gen Virol 79: 2157-2161, 1998.

109. Pan ZQ, Ge H, Amin AA and Hurwitz J: Transcription-positive cofactor 4 forms complexes with HSSB (RPA) on single-stranded DNA and influences HSSB-dependent enzymatic synthesis of simian virus 40 DNA. J Biol Chem 271: 22111-22116, 1996.

110. Saaf AM, Halbleib JM, Chen X, et al: Parallels between global transcriptional programs of polarizing Caco-2 intestinal epithelial cells in vitro and gene expression programs in normal colon and colon cancer. Mol Biol Cell 18: 4245-4260, 2007.

111. Kalkan A, Bulut V, Erel O, Avci S and Bingol NK: Adenosine deaminase and guanosine deaminase activities in sera of patients with viral hepatitis. Mem Inst Oswaldo Cruz 94: 383-386, 1999.

112.Firestein BL, Brenman JE, Aoki C, Sanchez-Perez AM, El-Husseini AE and Bredt DS: Cypin: a cytosolic regulator of PSD-95 postsynaptic targeting. Neuron 24: 659-672, 1999.

113. Nishikawa Y, Fukumoto K and Watanabe F: Guanine deaminase in serum as an indicator of survival probability in severe shock patients. Clin Chim Acta 131: 67-73, 1983

114.Ellis G and Goldberg DM: Serum guanase activities after myocardial infarction. Clin Chim Acta 63: 205-210, 1975

115. Ito S, Takaoka T, Kishi S, Nakaya Y, Hiasa Y and Mori H: Clinical and experimental studies of the determination of serum guanase activity in acute myocardial infarction. Jpn Circ J 45: $525-531,1981$

116.Jiang W, Cazacu S, Xiang C, et al: FK506 binding protein mediates glioma cell growth and sensitivity to rapamycin treatment by regulating NF-kappaB signaling pathway. Neoplasia 10: 235-243, 2008

117. Binder EB, Bradley RG, Liu W, et al: Association of FKBP5 polymorphisms and childhood abuse with risk of posttraumatic stress disorder symptoms in adults. JAMA 299: 1291-1305, 2008.

118. Yehuda R, Cai G, Golier JA, et al: Gene expression patterns associated with posttraumatic stress disorder following exposure to the World Trade Center attacks. Biol Psychiatry 66: 708-711, 2009.

119.Juric D, Lacayo NJ, Ramsey MC, et al: Differential gene expression patterns and interaction networks in BCR-ABLpositive and -negative adult acute lymphoblastic leukemias. J Clin Oncol 25: 1341-1349, 2007.

120. Wan D, Gong Y, Qin W, et al: Large-scale cDNA transfection screening for genes related to cancer development and progression. Proc Natl Acad Sci USA 101: 15724-15729, 2004.

121. Banerjee A, Stevenaert F, Pande K, et al: Modulation of paired immunoglobulin-like type 2 receptor signaling alters the host response to Staphylococcus aureus-induced pneumonia. Infect Immun 78: 1353-1363, 2010

122. Thomas R, Matthias T and Witte T: Leukocyte immunoglobulinlike receptors as new players in autoimmunity. Clin Rev Allergy Immunol 38: 159-162, 2009.

123.Bronstein JM, Tiwari-Woodruff S, Buznikov AG and Stevens DB: Involvement of OSP/claudin-11 in oligodendrocyte membrane interactions: role in biology and disease. J Neurosci Res 59: 706-711, 2000

124. Agarwal R, Mori Y, Cheng Y, et al: Silencing of claudin-11 is associated with increased invasiveness of gastric cancer cells. PLoS One 4: e8002, 2009.

125. Netzer C, Rieger L, Brero A, et al: SALL1, the gene mutated in Townes-Brocks syndrome, encodes a transcriptional repressor which interacts with TRF1/PIN2 and localizes to pericentromeric heterochromatin. Hum Mol Genet 10: 3017-3024, 2001. 
126. Sadikovic B, Yoshimoto M, Chilton-MacNeill S, Thorner P, Squire JA and Zielenska M: Identification of interactive networks of gene expression associated with osteosarcoma oncogenesis by integrated molecular profiling. Hum Mol Genet 18: $1962-1975,2009$.

127.Lien HC, Hsiao YH, Lin YS, et al: Molecular signatures of metaplastic carcinoma of the breast by large-scale transcriptional profiling: identification of genes potentially related to epithelial-mesenchymal transition. Oncogene 26: 7859-7871, 2007.

128. Lindholm E and Jazin E: A possible link between dopamine action and myelin dysfunction in schizophrenia. Schizophr Res 96: 271-272, 2007

129. Li ZZ, Kondo T, Murata T, et al: Expression of Hqk encoding a KH RNA binding protein is altered in human glioma. Jpn J Cancer Res 93: 167-177, 2002.

130. Geurts JM, Schoenmakers EF, Roijer E, Astrom AK, Stenman G and van de Ven WJ: Identification of NFIB as recurrent translocation partner gene of HMGIC in pleomorphic adenomas Oncogene 16: 865-872, 1998.

131. Pierron A, Fernandez C, Saada E, et al: HMGA2-NFIB fusion in a pediatric intramuscular lipoma: a novel case of NFIB alteration in a large deep-seated adipocytic tumor. Cancer Genet Cytogenet 195: 66-70, 2009.

132. Bian M, Yu M, Yang S, et al: Expression of Cbl-interacting protein of $85 \mathrm{kDa}$ in MPTP mouse model of Parkinson's disease and 1-methyl-4-phenyl-pyridinium ion-treated dopaminergic SH-SY5Y cells. Acta Biochim Biophys Sin 40: 505-512, 2008.

133. Lito P, Mets BD, Kleff S, O'Reilly S, Maher VM and McCormick JJ: Evidence that sprouty 2 is necessary for sarcoma formation by H-Ras oncogene-transformed human fibroblasts. J Biol Chem 283: 2002-2009, 2008.

134. Hamm A, Veeck J, Bektas N, et al: Frequent expression loss of Inter-alpha-trypsin inhibitor heavy chain (ITIH) genes in multiple human solid tumors: a systematic expression analysis. BMC Cancer 8: 25, 2008.

135. Ricciardelli C, Mayne K, Sykes PJ, et al: Elevated levels of versican but not decorin predict disease progression in earlystage prostate cancer. Clin Cancer Res 4: 963-971, 1998.

136. Theocharis AD: Versican in health and disease. Connect Tissue Res 49: 230-234, 2008

137. Meredith SP, Richards AJ, Flanagan DW, Scott JD, Poulson AV and Snead MP: Clinical characterisation and molecular analysis of Wagner syndrome. Br J Ophthalmol 91: 655-659, 2007.

138. Naschberger E, Croner RS, Merkel S, et al: Angiostatic immune reaction in colorectal carcinoma: Impact on survival and perspectives for antiangiogenic therapy. Int J Cancer 123 : 2120-2129, 2008
139. Riesewijk AM, Blagitko N, Schinzel AA, et al: Evidence against a major role of PEG1/MEST in Silver-Russell syndrome. Eur J Hum Genet 6: 114-120, 1998.

140.Lee EJ, Kong G, Lee SH, et al: Profiling of differentially expressed genes in human uterine leiomyomas. Int J Gynecol Cancer 15: 146-154, 2005.

141. Sjoblom T, Jones S, Wood LD, et al: The consensus coding sequences of human breast and colorectal cancers. Science 314: 268-274, 2006

142. Foulon V, Asselberghs S, Geens W, Mannaerts GP, Casteels M and Van Veldhoven PP: Further studies on the substrate spectrum of phytanoyl-CoA hydroxylase: implications for Refsum disease? J Lipid Res 44: 2349-2355, 2003.

143. Gad S, Teboul D, Lievre A, et al: Is the gene encoding Chibby implicated as a tumour suppressor in colorectal cancer? BMC Cancer 4: 31, 2004

144. Schuierer MM, Graf E, Takemaru K, Dietmaier W and Bosserhoff AK: Reduced expression of beta-catenin inhibitor Chibby in colon carcinoma cell lines. World J Gastroenterol 12: $1529-1535,2006$

145. Nibbe RK, Markowitz S, Myeroff L, Ewing R and Chance MR: Discovery and scoring of protein interaction subnetworks discriminative of late stage human colon cancer. Mol Cell Proteomics 8: 827-845, 2009

146. Mas VR, Archer KJ, Yanek K, et al: Gene expression patterns in deceased donor kidneys developing delayed graft function after kidney transplantation. Transplantation 85: 626-635, 2008.

147. Christensen GL, Ivanov IP, Atkins JF, Campbell B and Carrell DT: Identification of polymorphisms in the Hrb, GOPC, and Csnk2a2 genes in two men with globozoospermia. J Androl 27: 11-15, 2006.

148. Autieri MV, Carbone $\mathrm{C}$ and $\mathrm{Mu} \mathrm{A}$ : Expression of allograft inflammatory factor- 1 is a marker of activated human vascular smooth muscle cells and arterial injury. Arterioscler Thromb Vasc Biol 20: 1737-1744, 2000.

149. Tian Y, Kelemen SE and Autieri MV: Inhibition of AIF-1 expression by constitutive siRNA expression reduces macrophage migration, proliferation, and signal transduction initiated by atherogenic stimuli. Am J Physiol Cell Physiol 290: C1083-C1091, 2006.

150.Ji Y, Walkowicz MJ, Buiting K, et al: The ancestral gene for transcribed, low-copy repeats in the Prader-Willi/Angelman region encodes a large protein implicated in protein trafficking, which is deficient in mice with neuromuscular and spermiogenic abnormalities. Hum Mol Genet 8: 533-542, 1999. 